\title{
Challenges in developing regionalized characterization factors in land use impact assessment: impacts on ecosystem services in case studies of animal protein production in Sweden
}

\author{
Maria Nordborg $^{1} \cdot$ Yaw Sasu-Boakye $^{1} \cdot$ Christel Cederberg $^{1} \cdot$ Göran Berndes $^{1}$
}

Received: 10 June 2015 / Accepted: 25 May 2016 / Published online: 7 July 2016

(C) The Author(s) 2016. This article is published with open access at Springerlink.com

\begin{abstract}
Purpose The UNEP-SETAC Life Cycle Initiative has recently developed a guideline framework for land use impact assessment. This article evaluates the feasibility and highlights the challenges of applying a set of methods that adhere to this framework, and identifies the strengths and weaknesses of the indicators used in these methods, for the purpose of supporting further methodological development.

Methods The methods were tested in two case studies of animal protein production in Sweden: dairy milk and pork. The reference situations were defined as the potential natural vegetation. County-level characterization factors (CFs) were calculated and occupation impacts were assessed for five ecosystem services, using six ecosystem service indicators: carbon flow change, groundwater recharge, mechanical filtration capacity, physicochemical filtration capacity, soil loss, and soil organic carbon, at two geographic scales: county and biome. Strengths and weaknesses of the ecosystem service indicators were identified using an evaluation framework for selected quality characteristics: representativeness, reliability, feasibility, and transparency.

Results and discussion Occupation impacts at the two geographic scales, and for the two production cases, differ both
\end{abstract}

Responsible editor: Thomas Koellner

Electronic supplementary material The online version of this article (doi:10.1007/s11367-016-1158-x) contains supplementary material, which is available to authorized users.

Maria Nordborg

maria.nordborg@chalmers.se; maria.nordborg@gmail.com

1 Department of Energy and Environment, Division of Physical Resource Theory, Chalmers University of Technology, 412 96 Gothenburg, Sweden in absolute numbers, and - for mechanical and physicochemical filtration capacity - in the ranking of cases. Results at both geographic scales indicate positive effects-or lower negative impacts - in protein production from dairy milk compared to pork, due to grass production on dairy farms, and lower use of land per unit protein. However, some of the observed benefits may be exaggerated due to challenges in adequately representing the reference situations. Most indicators were assigned medium or high degrees of representativeness, feasibility, and transparency, but several were assigned low degrees of reliability, due to the weak scientific basis upon which they were selected, low degrees of accuracy, and insufficient information on how they should be assessed. Conclusions Occupation impact results should be interpreted with caution due to challenges in applying the methods and use of indicators with identified weaknesses. The most challenging part of developing regionalized CFs was finding suitable land areas from which to derive representative data to parameterize the reference situations. More research is needed to provide adequate support to life cycle assessment practitioners who wish to calculate regionalized CFs and to address the identified weaknesses.

Keywords Land use impact assessment - Life cycle assessment $\cdot$ Land use $\cdot$ Ecosystem services $\cdot$ Carbon flow change $\cdot$ Groundwater recharge $\cdot$ Mechanical filtration capacity $\cdot$ Physicochemical filtration capacity $\cdot$ Soil loss $\cdot$ Soil organic carbon $\cdot$ Reference situation $\cdot$ Potential natural vegetation

\section{Introduction}

Human-induced transformations of the atmosphere, hydrosphere, lithosphere, and biosphere have been so profound 
and widespread over the past three centuries that a new geological epoch has been suggested to represent the magnitude of these changes: the Anthropocene (Crutzen 2002). A majority of ecosystem services are currently being degraded or used unsustainably, and human land use has been identified as a major cause (MEA 2005).

Despite this, land use impacts on ecosystem services are often not included in life cycle assessment (LCA) studies of land-based products. Until recently, land use in agricultural LCAs was often only assessed at the inventory stage, i.e., in the form "area $\times$ time" (Milà i Canals et al. 2007). Such simple indicators have been judged "good initial proxies" of land use impacts in some studies (Milà i Canals et al. 2013) but inadequate in others (Helin et al. 2014).

The United Nations Environment Programme-Society for Environmental Toxicology and Chemistry (UNEPSETAC) Life Cycle Initiative has developed a guideline for land use impact assessment, which provides general principles aimed at supporting comprehensive and consistent assessments of impacts on biodiversity and ecosystem services due to land transformation (also called land use change) and occupation (also called land use) (Koellner et al. 2013). The guideline extends previous work within the Life Cycle Initiative (Milà i Canals et al. 2007) and provides globally applicable, ready-to-use characterization factors ( $\mathrm{CFs}$ ) for land use impacts on biodiversity and selected ecosystem services, at the biome level. One key feature of the methodology is the use of a reference situation, i.e., a baseline to which the quality of ecosystem services in the assessed land use situation is compared.

Within the EU, the European Commission is currently developing a Product Environmental Footprint (PEF) method for products and services. Within this work, available life cycle impact assessment methods for various impact categories (currently 15) are being evaluated. The impact assessment method for land use has been identified as inadequate and unsatisfactory, although it should be noted that this finding refers to the work by Milà i Canals et al. (2007) and not to the more recent UNEP-SETAC guideline (Lehmann et al. 2015). According to a mid-term review of the pilot phase of the PEF method development, the EU will release revised recommendations for the land use impact category by the end of 2016 (Lehmann et al. 2016).

Another recent development within the field, although beyond the scope of this study, is the conversion of the biophysical CFs of Koellner et al. (2013), into monetary units, based on the economic value of ecosystem services, or the costs associated with a reduction in the provision of ecosystem services (Cao et al. 2015). Economic valuation enables aggregation of different types of impacts and makes it easier for decision makers to interpret results, argued Cao et al. (2015).
Several recently published studies assess land use impacts, using a variety of different methods (see, e.g., Taelman et al. 2016; Saikku et al. 2015; Allacker et al. 2014; Coelho and Michelsen 2014; Elshout et al. 2014; Mueller et al. 2014; Michelsen et al. 2014; Helin et al. 2014; Milà i Canals et al. 2013; and Mattila et al. 2012). Three case studies use (at least partially) the proposed biome-level CFs: margarine production (Milà i Canals et al. 2013), biomass production for energy (Helin et al. 2014), and forestry plantations (Michelsen et al. 2014). These studies stress the need for regionalized CFs applicable to finer spatial scales than the biome level (Helin et al. 2014; Milà i Canals et al. 2013) and CFs that differentiate between management regimes and production intensities (Helin et al. 2014; Michelsen et al. 2014; Milà i Canals et al. 2013). Also, they stress that the methodology is in its infancy, with yet unproven utility in decision-making, and that results should be interpreted with caution (Helin et al. 2014; Michelsen et al. 2014; Milà i Canals et al. 2013). Helin et al. (2014) and Milà i Canals et al. (2013) discuss different options for defining the reference situations, and Milà i Canals et al. (2013) call for more case studies to evaluate the limits and potential flaws of the proposed methodological framework.

This article aims to (1) evaluate the feasibility of assessing land use impacts on ecosystem services at the regional scale by testing the models proposed by Koellner et al. (2013) on two case studies of animal protein production and (2) identify strengths and weaknesses of the ecosystem service indicators used in these models by evaluating the indicators in terms of selected qualities (representativeness, reliability, feasibility, and transparency). The purpose is to contribute to methodology development by identifying areas in need of further research.

\section{Materials and methods}

In order to evaluate the feasibility of assessing land use impacts on ecosystem services at the regional scale, county-level CFs were calculated and compared with published biome-level CFs, and reasons for observed differences were analyzed. Also, occupation impacts were calculated and interpreted, and reasons for differences between results at the two geographic scales (county and biome level), and between the two case studies, were analyzed. The case studies, as well as the methods used to calculate CFs and occupation impacts, are presented in Section 2.1.

In order to identify the strengths and weaknesses of the ecosystem service indicators used in the models proposed by Koellner et al. (2013), we developed and applied a framework for evaluation of selected quality characteristics. The framework is presented in Section 2.2. 


\subsection{Land use impact assessment in animal protein production}

\subsubsection{Case studies}

Case studies of animal protein production in two Swedish counties were considered: dairy milk in Västra Götaland (VG-dairy) and pork in Östergötland (OG-pork), both located in the northern part of biome 4 (temperate broadleaf and mixed forests), based on the biogeographical classification system of Olson et al. (2001) (Fig. 1).

The functional unit is $1 \mathrm{~kg}$ protein from dairy milk and pork, respectively. The system boundaries include land use for feed production but not land use associated with subsequent steps in the production chain. Land use requirements for feed production were based on a modified version of mainly local feed rations in Sasu-Boakye et al. (2014), in which minor amounts of imported soymeal and dried beet pulp were substituted with locally sourced feed ingredients while maintaining the rations' nutritional values. The annual production of $1 \mathrm{~kg}$ protein in VG-dairy requires $41 \mathrm{~m}^{2}$ of land, of which $40 \%$ is grassland and $60 \%$ cropland. The corresponding value for OG-pork is $58 \mathrm{~m}^{2}$, all of which is

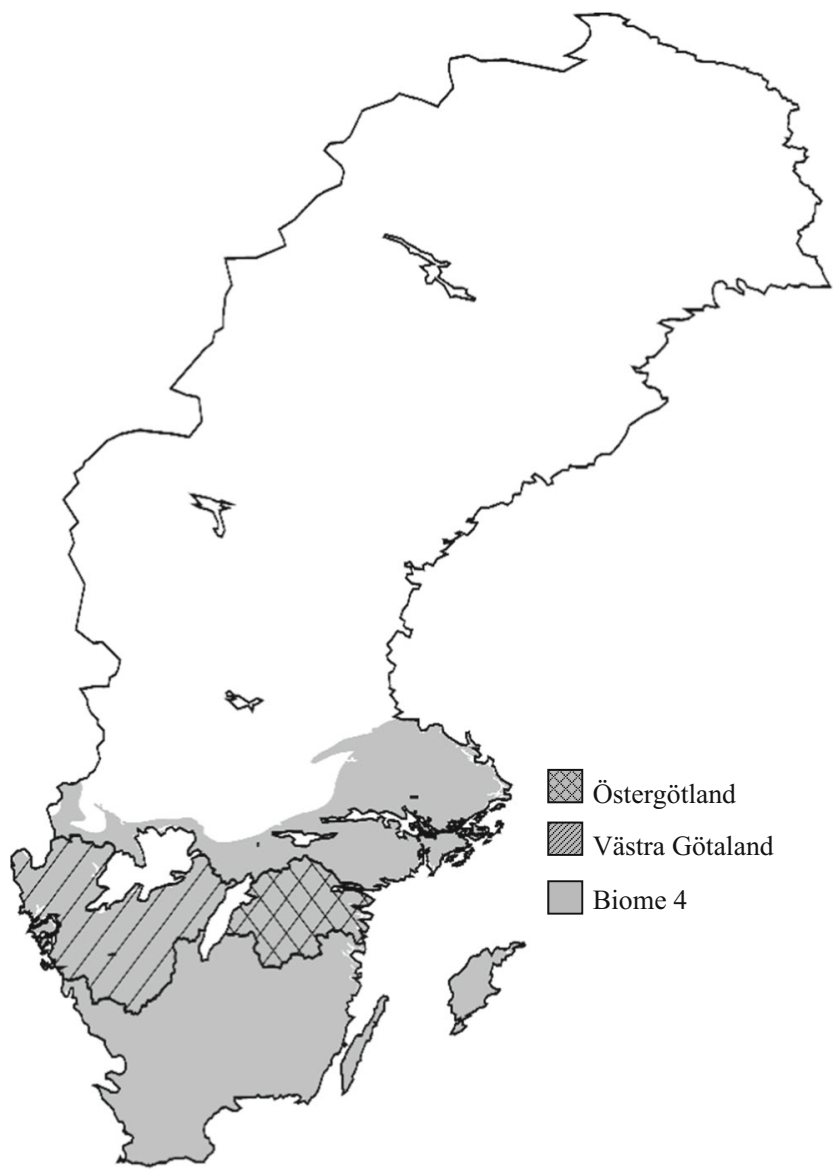

Fig. 1 Location of the studied counties and extent of biome 4 in Sweden. The full extent of biome 4 is shown in Fig. S1 (Electronic supplementary material S3) cropland. The grassland consists of grass and clover leys, typically in 5-year rotation ( 3 years of ley and 2 years of cereal), used for silage production and pasture. More information on feed rations and land use requirements is available in Electronic supplementary material $\mathrm{S} 1$.

There is no land transformation in either case, based on the decision tree in Milà i Canals et al. (2013), since all feed items are locally produced on nonexpanding agricultural land in Sweden. Hence, only occupation impacts are included. Impacts on biodiversity are not included.

\subsubsection{Definition of reference situation}

The UNEP-SETAC guideline requires a reference situation, i.e., a baseline to which the quality level of ecosystem services in the assessed land use situation can be compared (Koellner et al. 2013). We defined the reference situation as the potential natural vegetation (PNV), which "describes the expected state of mature vegetation in the absence of human intervention" (Koellner et al. 2013). More specifically, we defined this as a point in history before the assessed land use was initiated, and determined the PNV as deciduous (broadleaf) forest in both $\mathrm{VG}$ and $\mathrm{OG}$, based on records of the historic vegetation in Sweden (see Electronic supplementary material S2).

\subsubsection{Calculation of county-level characterization factors}

County-level CFs were calculated for five ecosystem services - climate regulation, freshwater regulation, freshwater purification, erosion prevention, and biotic production potential-using six ecosystem service indicators - carbon flow change (CFC), groundwater recharge (GWR), mechanical filtration capacity (MFC), physicochemical filtration capacity (PFC), soil loss (SL), and soil organic carbon (SOC) (Table 1). These ecosystem services and corresponding indicators were selected because they represent the full suite for which operational models consistent with the UNEP-SETAC guideline for land use impact assessment of ecosystem services, and ready-to-use CFs at the biome level, are available (Koellner et al. 2013). However, other ecosystem services may be equally or more important from an environmental and/or a policy perspective. Generally, CFs were calculated as the difference in quality between the reference and the assessed land use situations following Koellner et al. (2013) (except for CFC, see Electronic supplementary material S7).

Since using the models cited in Table 1 involves interpreting and making subjective choices, the Electronic supplementary materials S5-14 provide a detailed description of how CFs were calculated and introduce the fundamental principles of land use impact assessment (S4).

The land use indicator value calculation (LANCA) model has been recommended for calculating CFs for GWR, MFC, PFC, and SL by Koellner et al. (2013). In LANCA, CFs for 


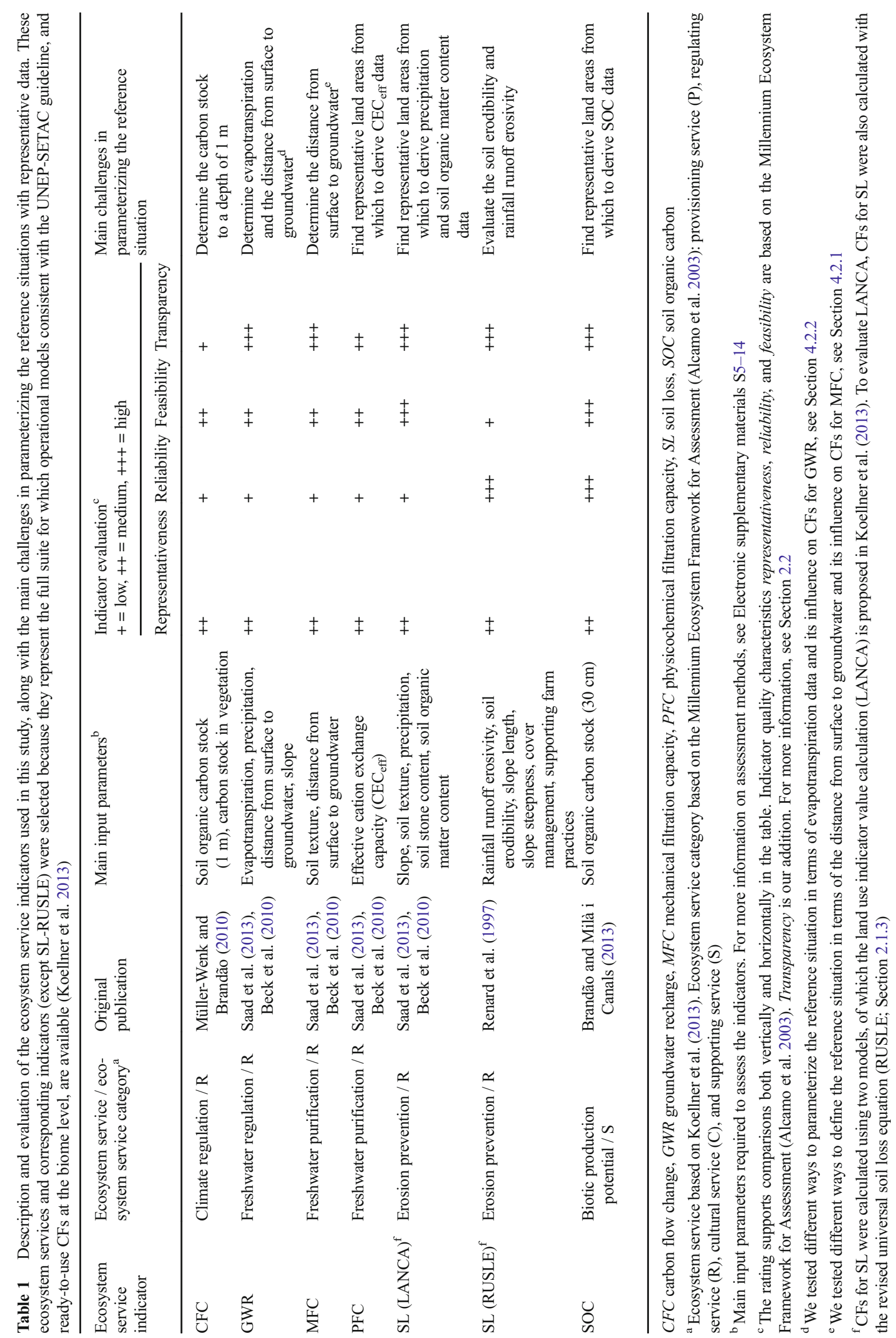


SL are calculated based on a simplified version of the universal soil loss equation (USLE) (Beck et al. 2010). To evaluate this approach, we also calculated CFs for SL with the revised universal soil loss equation (RUSLE) (Renard et al. 1997) integrated into ArcGIS (see Electronic supplementary material S12).

The main data sources are presented in Table 2. All data used and additional information (number of data points, maximum and minimum values, as well as standard deviations for several of the main input parameters) are available in Electronic supplementary materials S5-14.

In parameterizing the reference situations with representative data (i.e., assigning data that represent conditions in the reference situations), we followed the approach of Milà i Canals et al. (2007). Specifically, conditions in neighboring land areas in a natural or near-tonatural state were assumed to represent reference conditions at the studied locations in the absence of the assessed land uses. For more information, see Electronic supplementary materials S6-14.

We assessed the sensitivities to a selection of key input parameters used in calculating CFs for GWR and MFC (evapotranspiration and the distance from surface to groundwater). These analyses are presented and discussed in Section 4.2.

Table 2 Data sources for derivation of data for main input parameters in the calculation of county-level CFs (data sources used to calculate CFs for SL using RUSLE are available in Electronic supplementary material S12). All data that we used and additional information (number of data

\begin{tabular}{ll}
\hline Data category & Parameters \\
\hline Soil data & $\begin{array}{l}\text { Soil organic carbon stocks, soil } \\
\text { organic matter content, and } \\
\text { effective cation exchange capacity }\left(\mathrm{CEC}_{\mathrm{eff}}\right)\end{array}$
\end{tabular}

Soil texture

Soil stone contents

Climate data Evapotranspiration

Precipitation

Other data Carbon stocks in vegetation

Distance from surface to groundwater

Slope

\subsubsection{Calculation of occupation impacts}

Following Koellner et al. (2013), occupation impacts per functional unit were calculated by multiplying CFs with inventory flows (Eq. 1), which consist of the time (T; in years) and area $\left(A\right.$; in $\left.\mathrm{m}^{2}\right)$ extensions of land use per functional unit.

Occupation impact $=\mathrm{CF} \cdot A \cdot T$

\subsection{Evaluating ecosystem service indicators}

The linkages between ecosystem change and human wellbeing were assessed in MEA (2005) using a conceptual assessment framework developed by Alcamo et al. (2003). This framework aims to assist in selecting appropriate indicators of ecosystem conditions, services, and drivers of change, and states that "good" ecosystem service indicators share some common characteristics, namely, representativeness, reliability, and feasibility (Alcamo et al. 2003). We added transparency as a fourth characteristic and evaluated the ecosystem service indicators used in the case studies in order to identify their strengths and weaknesses.

points, maximum and minimum values, as well as standard deviations for several of the main input parameters) are available in Electronic supplementary materials S5-14

Data sources

Swedish Agricultural Soil and Crop Inventory

(Eriksson et al. 2010, http://www-jordbruksmark.slu.se/)

for agricultural soils (used for parameterizing the assessed land use situations). Swedish Forest Soil Inventory

(www.markinfo.slu.se/; Stendahl, 2014, personal communication) for forest soils (used for parameterizing the reference situations). Carbon stocks extrapolated to $1 \mathrm{~m}$ depth based on Jobbágy and Jackson (2000)

Swedish Agricultural Soil and Crop Inventory (Eriksson et al. 2010, http://www-jordbruksmark.slu.se/) for both the reference and the assessed land use situations

Rytter (2012) for agricultural soils (used for parameterizing the assessed land use situations). Eriksson and Holmgren (1996) and Stendahl et al. (2009) for forest soils (used for parameterizing the reference situations)

Global map of yearly actual evapotranspiration (FAO 2009), using ArcGIS and land cover data from Büttner and Kosztra (2007)

Hijmans et al. (2005), using ArcGIS and land cover data from Büttner and Kosztra (2007)

Official Swedish forest statistics (Nilsson et al. 2014)

Thunholm and Sundén, 2014, personal communication, Geological Survey of Sweden

Jarvis et al. (2008), using ArcGIS 
The evaluation targets the ecosystem service indicators (Table 1) on a conceptual level, not the CFs or the occupation impact results derived from these indicators. Since Alcamo et al. (2003) only give limited guidance on how the various qualities should be interpreted and evaluated in practice, we developed more detailed interpretations, described below. We acknowledge that alternative interpretations may exist. The evaluations and ratings are based on our experience and are hence subjective.

\subsubsection{Representativeness}

Representativeness was evaluated as the degree to which the indicator (1) covers "the most important aspects of ecosystems and their services," (2) is "a sign of the degree to which an objective of an ecosystem service is met," and 3) illustrates "trends in ecosystems and their services over time, as well as differences between places" (Alcamo et al. 2003).

For part (1), we considered the relevance of the indicator on a conceptual level, in relation to the ecosystem service it is supposed to measure, i.e., to what degree the indicator is a representative indicator for the ecosystem service in question. We did not consider the assessment method or the data used. For part (2), we considered whether the indicator expresses the result in relation to a goal or threshold, thereby supporting an evaluation of the performance in relative terms. For part (3), we considered whether the indicator (on a conceptual level), and the individual input parameters that are required for calculating it, can capture differences in space and time. We did not consider availability or accessibility of data. An overall rating (low, medium, high) was assigned based on a qualitative aggregation of these three parts.

\subsubsection{Reliability}

Reliability was evaluated as the degree to which the indicator is (1) "well-founded," (2) "accurate," and (3) "measured in a standardized way using an established or peer-reviewed method and sound and consistent sampling procedures" (Alcamo et al. 2003).

For part (1), we considered the motivations (scientific basis) for choosing the indicator and its specific assessment method (both with regard to input parameters and data demand), as provided in the original publications, i.e., to what degree the original publications answer the question "Why is this ecosystem service evaluated using this indicator, and why is this indicator assessed using these specific equation(s) and data?". For part (2), we considered to what degree the indicator provides a true and precise representation of reality, considering the assessment method. For part (3), we considered the assessment method based on the information in the original publications, in relation to the assessed land use situation. We did not consider challenges associated with the definition and parameterization of the reference situation. An overall rating (low, medium, high) was assigned based on a qualitative aggregation of these three parts.

\subsubsection{Feasibility}

Feasibility was evaluated as the degree to which the indicator depends on "data that are readily available or obtainable at reasonable cost" (Alcamo et al. 2003). We evaluated the feasibility of each main input parameter separately and assigned an overall rating (low, medium, high) based on an aggregation of the ratings of the individual input parameters and the total data demand.

\subsubsection{Transparency}

Transparency was evaluated as the degree to which the indicator is easily interpretable and communicable to stakeholders lacking expert knowledge in LCA or associated scientific areas (our definition). An overall rating (low, medium, high) was assigned based on a qualitative evaluation of how easy or difficult it would be to explain what the indicator represents and what information it conveys to an external stakeholder. In this evaluation, we considered the indicator on a conceptual level. We did not consider the assessment method, the CFs, or the occupation impact results derived from the indicator.

\section{Results}

County-level CFs are presented in Section 3.1. Land use occupation impacts in the case studies are presented in Section 3.2. Results from the indicator evaluation are presented in Section 3.3.

\subsection{Characterization factors}

Here, we present the calculated CFs (Table 3) and analyze and explain the reasons for the observed differences between county- and biome-level CFs, between county-level CFs for cropland in VG and OG, and between county-level CFs for cropland and grassland in VG. For GWR, MFC, PFC, and SL, the observed differences between county- and biome-level CFs could not easily be explained; this is discussed further in Section 4.1.

County- and biome-level CFs for CFC, MFC, SL, and SOC fall within the same order of magnitude, while CFs for GWR and PFC differ by up to one order of magnitude (Table 3 ). County-level CFs are consistently lower than biome-level $\mathrm{CFs}$, indicating lesser negative impacts or greater positive effects (i.e., ecosystem service improvements). 
Table 3 County- and biome-level CFs for impact assessment of land occupation on ecosystem services. For SL, two different models were used to calculate county-level CFs

\begin{tabular}{|c|c|c|c|c|c|c|}
\hline \multirow[t]{3}{*}{ Ecosystem service indicator } & \multirow[t]{3}{*}{ Unit } & \multicolumn{3}{|c|}{ County-level CFs (calculated in this study) } & \multicolumn{2}{|c|}{ Biome-level CFs for biome $4^{\mathrm{c}}$} \\
\hline & & \multicolumn{2}{|l|}{ VG-dairy $^{\mathrm{a}}$} & \multirow{2}{*}{$\begin{array}{l}\text { OG-pork }{ }^{\mathrm{b}} \\
\text { Cropland }^{\mathrm{d}}\end{array}$} & \multirow[t]{2}{*}{ Cropland $^{\mathrm{f}}$} & \multirow[t]{2}{*}{ Grassland $^{\mathrm{g}}$} \\
\hline & & Cropland $^{\mathrm{d}}$ & Grassland $^{\mathrm{e}}$ & & & \\
\hline $\mathrm{CFC}$ & tonne $\mathrm{ha}^{-1}$ of carbon & 0.53 & 0.42 & 0.50 & 0.86 & 0.64 \\
\hline GWR & $\mathrm{mm}_{\text {year }}^{-1}$ of water & 10.6 & -5.00 & 32.9 & 127 & 127 \\
\hline MFC & $\mathrm{cm} \mathrm{day}^{-1}$ of water & 1.25 & 0 & 0.28 & 1.34 & 1.34 \\
\hline PFC & $\mathrm{cmol} \mathrm{kg}^{-1}$ of positive charges per dry soil & -7.26 & -7.82 & -11.8 & 0.85 & 0.85 \\
\hline SL (LANCA) & tonne ha $^{-1}$ year $^{-1}$ of soil & 6.95 & 1.95 & 6.95 & 40.2 & 18.1 \\
\hline SL $\left(\right.$ RUSLE) ${ }^{\mathrm{h}}$ & tonne $\mathrm{ha}^{-1}$ year $^{-1}$ of soil & 0.07 & 0.01 & 0.04 & & \\
\hline SOC & tonne $\mathrm{ha}^{-1}$ of carbon & -30.1 & -30.1 & -25.5 & $-6.90^{\mathrm{i}}$ & $-13.0^{\mathrm{j}}$ \\
\hline
\end{tabular}

$C F C$ carbon flow change, GWR groundwater recharge, $M F C$ mechanical filtration capacity, $P F C$ physicochemical filtration capacity, $S L$ soil loss, SOC soil organic carbon

${ }^{a}$ Protein production from dairy milk in the county of Västra Götaland, Sweden

${ }^{\mathrm{b}}$ Protein production from pork in the county of Östergötland, Sweden

${ }^{\mathrm{c}} \mathrm{CFs}$ for biome 4 (temperate broadleaf and mixed forests) were downloaded from Excel files embedded in the Electronic supplementary material of the UNEP-SETAC guideline on land use impact assessment (Koellner et al. 2013), except for SOC (see footnotes $\mathrm{i}$ and $\mathrm{j}$ )

${ }^{\mathrm{d}}$ Called "farmland (no complete surface vegetation)" in LANCA

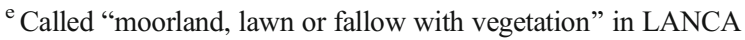

${ }^{\mathrm{f}}$ Called "agriculture, permanent crops" for GWR, MFC, PFC, and SL and "Agriculture, arable" for CFC, in Excel files from which CFs were obtained

"Called "grassland, pasture/meadow" for GWR, MFC, PFC, and SL and "Agriculture, arable" for CFC, in Excel files from which CFs were obtained

${ }^{\mathrm{h}} \mathrm{CFs}$ for SL calculated with RUSLE have no biome-level counterpart

${ }^{i}$ Koellner et al. (2013) reclassified the CFs for SOC calculated in Brandão and Milà i Canals (2013) to match the biome regions. However, the CF for cropland in biome 4 was incorrectly calculated in the reclassification. We corrected this mistake and calculated a new biome-level CF for long-term cultivated land with high input of manure and reduced tillage in biome 4 (Electronic supplementary material S13.2)

${ }^{\mathrm{j}}$ Brandão and Milà i Canals (2013) considered the influence of land use, farm management regimes, and organic matter input in the calculation of biomelevel CFs for SOC. However, the impact of management regimes on SOC was mistakenly omitted in the calculation of biome-level CFs for managed grasslands. We corrected this mistake and calculated a new biome-level CF for improved grassland with medium input of manure in biome 4 (Electronic supplementary material S13.2)

Comparing county-level CFs for cropland and grassland in VG for GWR, MFC, and PFC, the differences are entirely due to a higher degree of sealing in cropland than in grassland, i.e., less water can infiltrate cropland soils (due to compaction) and become available for purification and groundwater recharge.

\subsubsection{Carbon flow change}

Positive CFs represent a loss in the carbon sequestration potential of ecosystems. County-level CFs indicate lesser negative impacts than biome-level CFs (Table 3) due to lower carbon stocks in soil and vegetation in the reference situations in $\mathrm{VG}$ and $\mathrm{OG}$ than the stocks that Müller-Wenk and Brandão (2010) used for biome 4.

There is considerable difference between county-level CFs for cropland in VG and OG. CFs at both scales indicate a greater negative impact on cropland than on grassland, which is in line with the view that conversion of forest to cropland causes larger ecosystem carbon losses than conversion to grassland (Guo and Gifford 2002).

\subsubsection{Groundwater recharge}

Positive CFs represent the amount of groundwater that is potentially not recharged annually, due to land occupation (ecosystem service impairment), while negative CFs represent the additional amount of water that is potentially recharged annually due to land occupation (ecosystem service improvement).

Biome-level CFs indicate greater negative impacts than county-level CFs (Table 3). At the county level, the CF for cropland in $\mathrm{OG}$ is three times larger than in VG, due to a greater relative reduction in recharging capacity in OG.

The difference between county-level CFs for cropland in $\mathrm{VG}$ and $\mathrm{OG}$ is mainly due to that the difference in evapotranspiration levels between the reference and the assessed land use situation is larger in $\mathrm{OG}$ than in $\mathrm{VG}$ (precipitation levels do not contribute since they were kept fixed, see Electronic supplementary material S8). The influence of different choices in parameterizing the reference situations with evapotranspiration data is evaluated and further discussed in Section 4.2.2. 
The CF for grassland in VG indicates an ecosystem service improvement compared to the reference situation. This is because evapotranspiration is lower in the assessed land use situation than in the reference situation (Table S8, Electronic supplementary material S8.1); hence, more water becomes available for groundwater recharge, ceteris paribus.

\subsubsection{Mechanical filtration capacity}

Positive CFs represent the amount of water that is potentially not mechanically filtrated, due to land occupation (an ecosystem service impairment). All CFs are positive, but countylevel CFs indicate lesser negative impacts than biome-level CFs (Table 3).

County-level CFs for cropland indicate a greater negative impact in VG than in OG, due to more sandy-and hence more permeable-cropland soils in VG (Table S11, Electronic supplementary material S9.1) (further discussed in Section 4.3). The CF for grassland in VG indicates no impact, compared to the reference situation. This is because it was assumed that the soil texture remains fixed over time, and because both grasslands and woodlands are considered equally capable of infiltrating water in LANCA (Table S29, Electronic supplementary material S14).

\subsubsection{Physicochemical filtration capacity}

Positive biome-level CFs represent the moles of cation charges that are potentially lost, due to land occupation (ecosystem service impairment), while negative county-level CFs represent the moles of additional cation charges that are potentially fixed due to land occupation (ecosystem service improvement).

County- and biome-level CFs differ both in sign and order of magnitude (Table 3). County-level CFs are negative due to the use of $\mathrm{CEC}_{\mathrm{eff}}$ data that most probably underestimate reference conditions, caused by challenges in finding suitable land areas from which to derive representative data, further discussed in Section 4.2.2.

County-level CFs indicate a more positive effect on cropland in OG, than in VG, due to more clayey cropland soils in OG (associated with a higher $\mathrm{CEC}_{\text {eff }}$ ) in combination with almost similar quality levels in the respective reference situations. Thus, cropland use in $\mathrm{OG}$ is associated with a relatively greater increase in the capacity of the soil to physicochemically purify water. However, this result should be interpreted with caution considering that reference conditions are probably underestimated (see Section 4.2.2).

\subsubsection{Soil loss}

Positive CFs indicate the additional mass of soil potentially eroded, due to land occupation (ecosystem service impairment). All CFs are positive (Table 3), but the magnitudes are different across the three sets of CFs, and decrease as the spatial resolution increases. The CF for cropland in $\mathrm{VG}$ calculated with LANCA (SL-LANCA) indicates an annual soil loss of 7 tonnes ha ${ }^{-1}$ (compared to the reference situation), while the corresponding value calculated with RUSLE (SLRUSLE) indicates an annual soil loss of only 0.07 tonnes ha ${ }^{-1}$ (Table 3). This difference is mainly due to RUSLE taking reduced tillage into account (which LANCA does not). These results can be compared with modeled annual erosion rates of 0-2 tonnes $\mathrm{ha}^{-1}$ for arable land in $\mathrm{VG}$, based on RUSLE (JRC 2012), and measured annual erosion rates of 0-2 tonnes ha ${ }^{-1}$ for arable land in Sweden (Cerdan et al. 2010). When we considered a mix of tillage systems, the CFs calculated with RUSLE increased by a factor of 10 , making them comparable to the results from JRC (2012) and Cerdan et al. (2010).

County-level CFs calculated with RUSLE indicate a greater negative impact on cropland in VG than in OG, mainly due to a higher precipitation rate in VG (Table S9, Electronic supplementary material S8.1). County-level CFs calculated with LANCA do not capture these relatively small, but significant, regional differences in precipitation.

County-level CFs for grassland are considerably lower than for cropland, indicating lower soil erosion for roughage fodder crops than for annual feed grains. This is expected since grasslands provide a more complete vegetation cover over the year than cropland.

\subsubsection{Soil organic carbon}

Negative CFs indicate an increase in the potential capacity of ecosystems to support biomass production, due to larger SOC stocks in the assessed land use situations than the reference situations (Table 3). County-level CFs indicate a greater positive effect on cropland in VG than in OG, due to an average 0.5-1 percentage points higher content of organic matter in soils on dairy farms than on arable and pig farms, mainly due to grass cultivation on dairy farms (Eriksson et al. 2010). Trends in Danish agricultural soils over a period of 10 12 years have shown similar results: SOC stocks increased on dairy farms and decreased on arable and pig farms (Heidmann et al. 2002).

County-level CFs indicate greater positive effects than biome-level CFs, but these positive effects are probably exaggerated, due to challenges in finding suitable land areas from which to derive representative data (see Section 4.2.2).

Improved biotic production potentials, as suggested by the CFs for SOC, contradict research showing that conversion of natural lands into agricultural land has resulted in significant losses of SOC globally (Wei et al. 2014; Yang et al. 2003). One explanation is that we considered cropland with a high input of manure. At the biome level, this is also due to that 
Brandão and Milà i Canals (2013) probably exaggerated the benefits of reduced tillage on SOC stocks (see Section 4.3).

\subsection{Occupation impacts}

Here, we present land use occupation impact results (Fig. 2) and analyze the reasons for the differences between results at the two geographic scales (county and biome level) and between the two production cases (VG-dairy and OG-pork).

Occupation impacts calculated with CFs at the two geographic scales, and for the two production cases, differ both in absolute numbers, and-for two indicators of water purification (MFC and PFC) - in the ranking of cases, i.e., results flip across scales and cases (Fig. 2).

Occupation impacts at both scales calculated with CFs for CFC, GWR, SL, and SOC are consistent in ranking the cases. Results for CFC, GWR, and SL show that OG-pork has greater negative impacts per unit protein than VG-dairy, for both sets of CFs. This is because (1) VG-dairy is a more areaefficient form of protein production than OG-pork, (2) $40 \%$ of the land use in VG-dairy consists of grassland, and (3) grass production is less damaging, or more beneficial, than crop production, as indicated by the CFs for CFC, GWR, and SL (Table 3).

For MFC and PFC, occupation impacts calculated with the two sets of CFs are inconsistent. For MFC, results at the biome level indicate that VG-dairy is associated with a lesser negative impact than OG-pork, while results at the county level indicate the opposite, despite that VG-dairy requires less land than OG-pork (Section 2.1.1) and no impact is attributed to grassland (Table 3). These county-level results are due to a greater negative impact associated with cropland in VG than in OG (Table 3), which outweighs the lower use of cropland in VG. For PFC, occupation impact results are inconsistent across scales and cases primarily because biome-level CFs are positive, while county-level CFs are negative (Section 3.1.4).

Only one indicator (SOC) consistently shows that OG-pork is more beneficial than VG-dairy, at both scales, despite higher content of organic matter in soils on dairy farms (Section 3.1.6). Recalling that occupation impacts are the product of CFs and inventory flows (Section 2.1.4), this somewhat counterintuitive result is mainly due to OG-pork requiring more land per unit protein, i.e., the (relatively smaller) positive effect of higher content of organic matter on dairy farms is outweighed by more land use in OG-pork.

Occupation impacts for SL calculated with RUSLE yield the same ranking of the two cases as LANCA but with much smaller values (Electronic supplementary material S12).

Considering the results for SL and SOC, Fig. 2 suggests that the assessed land use situations simultaneously cause soil loss and increased biotic production potential relative to the reference situations (at both scales). This is inconsistent with research showing that soil erosion is associated with a loss in SOC stocks, hence a loss in the potential capacity of ecosystems to support biomass production (Yang et al. 2003). These
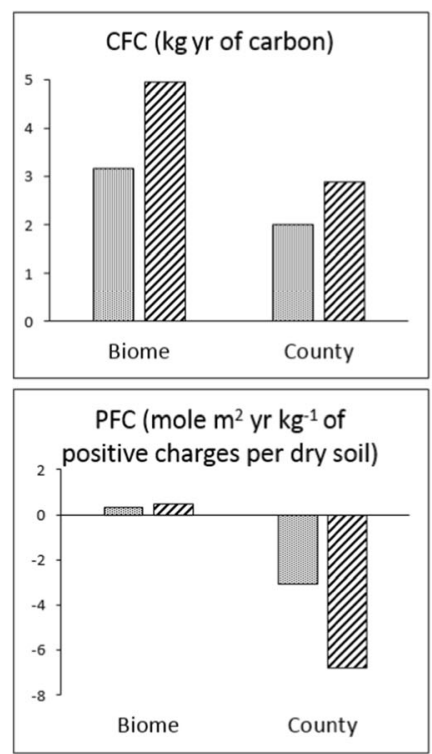
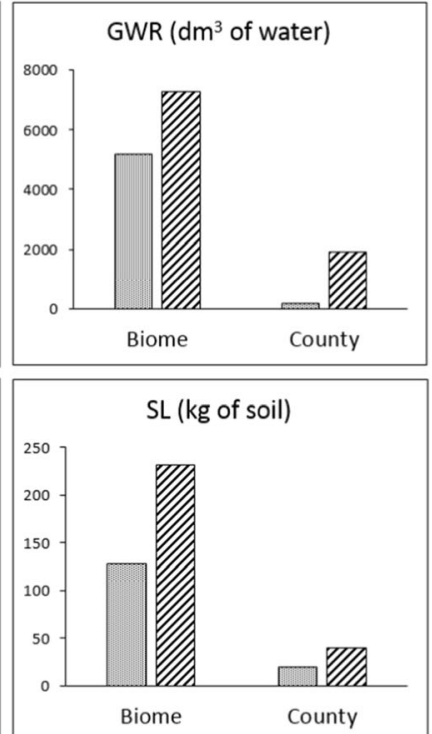

County
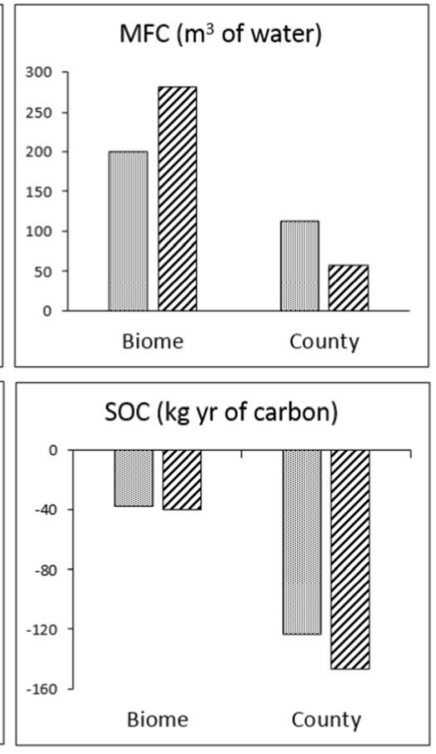

VG-dairy

Fig. 2 Occupation impacts on ecosystem services due to production of $1 \mathrm{~kg}$ protein from dairy milk in the county of Västra Götaland, Sweden (VG-dairy), and from pork in the county of Östergötland, Sweden (OGpork). The reference situation is the potential natural vegetation, defined as deciduous (broadleaf) forest. Occupation impacts are calculated with (1) county-level characterization factors (CFs) developed in this study

and (2) biome-level CFs for biome 4 (temperate broadleaf and mixed forests) from Koellner et al. (2013) (see Table 3). CFC carbon flow change, $G W R$ groundwater recharge, $M F C$ mechanical filtration capacity, $P F C$ physicochemical filtration capacity, $S L$ soil loss, $S O C$ soil organic carbon. Occupation impacts for SL shown here were calculated using LANCA 
inconsistent results stem from considering cropland with a high input of manure in combination with, at the county level, probably underestimated reference SOC stocks (see Section 4.2.2) and, at the biome level, a probably exaggerated benefit of reduced tillage on SOC stocks in the assessed land use situations (Section 3.1.6).

Taken together, occupation impacts at both geographic scales indicate positive effects - or lower negative impactsin protein production from dairy milk compared to pork, due to grass production on dairy farms, and lower use of land per unit protein. However, some of the observed benefits (for PFC and SOC) may be exaggerated due to challenges in adequately representing the reference situations.

\subsection{Evaluation of ecosystem service indicators}

\subsubsection{Representativeness}

All indicators were assigned medium degrees of representativeness (Table 1); all are relevant indicators (on a conceptual level), but none is "a sign of the degree to which an objective of an ecosystem service is met" (Section 2.2.1), i.e., relates the result to a goal or a threshold, thereby supporting an evaluation of the performance in relative terms. Relating conditions to a goal or a threshold is important due to varying environmental conditions and sensitivities, and because a certain level of impact may cause large damage in one region and less damage in another. The construction of impact indicators from ecosystem service indicators, i.e., the calculation of $\mathrm{CFs}$, aims to fulfill this criterion, but challenges associated with setting a relevant baseline (i.e., a reference situation) potentially undermine the relevance of the $\mathrm{CFs}$.

All indicators are (fully or partially) capable of capturing "trends in ecosystems and their services over time, as well as differences between places." For example, CFC only partially captures spatiotemporal differences, due to the assumption in Müller-Wenk and Brandão (2010) that land use management is carbon neutral, which prevents different forms of land management from being distinguished in this regard.

\subsubsection{Reliability}

Most indicators were assigned low reliability scores, except SOC and SL-RUSLE (Table 1). In order for ecosystem service indicators to be successfully adopted, it is important that users (in this case LCA practitioners) understand why the indicators are chosen, and why they are assessed as they are. For GWR, MFC, PFC, and SL, Koellner et al. (2013) refer to Saad et al. (2013), who adopted an existing model, LANCA, described in Beck et al. (2010), and developed based on Baitz (2002). The scientific basis for adopting these indicators could not be established by reviewing these publications. On the other hand, Brandão and Milà i Canals (2013) convincingly argue that $\mathrm{SOC}$ is a relevant indicator for biotic production potential, as do Renard et al. (1997) for soil loss calculated with RUSLE. Therefore, only SOC and SL-RUSLE were found to be wellfounded.

With regard to accuracy, LANCA assesses SL less accurately than RUSLE, since the former is based on a simplified version of USLE that uses coarse data to represent large regions (Section 2.1.3). Also, the simplified version of GWR that we used (Electronic supplementary material S8) has a low degree of accuracy since it does not take into account the available field capacity, influence by the soil texture. Further, the accuracy of MFC is uncertain, as discussed in Section 4.2.1.

With regard to standardization, Renard et al. (1997) and Brandão and Milà i Canals (2013) describe in sufficient detail how SL-RUSLE and SOC should be assessed (what data to use, etc.). In contrast, the original publications for MFC, PFC, and SL-LANCA (Table 1) do not state what soil depth to derive soil data from, which is a serious shortcoming.

\subsubsection{Feasibility}

Most indicators were assigned medium (CFC, GWR, MFC, and PFC) or high (SL-LANCA, SOC) degrees of feasibility, except SL-RUSLE (low degree; Table 1). The reason is that RUSLE requires large amounts of data that are not always readily available or obtainable at reasonable cost (time, effort). For example, rainfall runoff erosivity requires data on rainfall intensity and temperature with a high level of spatiotemporal resolution (data records at $15 \mathrm{~min}$ intervals over a period of 20 years). These data are seldom available, and when they are, they are very resource-intensive to process. The feasibility scores can be interpreted as an indication of the time required by LCA practitioners to calculate new CFs in LCA studies.

The medium to high feasibility is partly a consequence of performing this case study in Sweden. The Swedish Environmental Protection Agency's national environmental monitoring program has time series for some environmental variables that are among the longest in the world (SEPA 2014a). The Swedish forest biomass has for example been regularly monitored since 1923 (Fridman et al. 2014). Despite the relatively favorable situation, data that represent the reference situation are nevertheless limited: 14 and 18 soil samples may not be sufficient for deriving representative averages, as done for $\mathrm{CEC}_{\text {eff }}$ in the reference situations in $\mathrm{OG}$ and VG, respectively (Table S12, Electronic supplementary material S10.1).

Finding data that are both representative of the situations under study, and at the required resolution, is one of the main challenges in developing regionalized $\mathrm{CFs}$. However, gradually, data availability increases, whether it is measured, remotely sensed, modeled, or open source with multiple spatial and temporal resolutions (such as Hijmans et al. 2005, Jarvis 
et al. 2008, and Shangguan et al. 2014). While this development is beneficial, it introduces another challenge when it comes to combining data from different sources: datasets with similar resolutions can display significant variations in values associated with different methods to derive data (Herold et al. 2006; Verburg et al. 2011). It is important to ensure consistency when using data from different sources and to communicate the uncertainties that may arise from any inconsistencies.

\subsubsection{Transparency}

Most indicators were assigned medium (PFC) or high (GWR, MFC, SL-LANCA, SL-RUSLE, and SOC) degrees of transparency, i.e., the indicators are considered communicable to stakeholders and fairly easily interpretable (Table 1). This is because water volume, soil mass, and SOC are quantities to which most stakeholders can intuitively relate. PFC has been assigned a medium degree of transparency because the $\mathrm{CEC}_{\text {eff }}$ concept is less well known. Only one indicator, CFC, has been assigned a low degree of transparency, because the concept of a duration time of carbon in the atmosphere, in relation to fossil-combustion-equivalent carbon, requires some level of expertise to comprehend.

\section{Discussion}

Here, we discuss challenges in comparing county- and biomelevel CFs (Section 4.1), challenges in setting the reference situations and whether an alternative reference situation would be more informative (Section 4.2), and results from the indicator evaluation and associated uncertainties (Section 4.3).

\subsection{Challenges in comparing county- and biome-level CFs}

In Section 3.1, we analyzed the reasons for the observed differences between county- and biome-level CFs for CFC and SOC. However, for CFs calculated with LANCA (GWR, MFC, PFC, and SL), sufficient information was not available in Saad et al. (2013) to support a similar analysis and could not be obtained (Saad, 2014, personal communication). For example, we were unable to determine how the reference situations had been parameterized with regard to data on $\mathrm{CEC}_{\text {eff }}$, precipitation, and evapotranspiration and whether soil textures were the same in the reference as in the assessed land use situations. Possible reasons for the observed differences are discussed below.

Biome-level CFs for MFC and PFC were calculated with soil data from the top $30 \mathrm{~cm}$ of the soil (Saad, 2014, personal communication), which we were not able to match, due to limited data availability (Electronic supplementary materials S09-10). Thus, different soil depths from which soil data were derived may explain some of the observed differences for $\mathrm{CFs}$ for MFC and PFC. The literature (Table 1) provides very limited guidance on this matter, even though many soil properties vary with depth. For GWR, MFC, and PFC, no recommended soil depth is even stated (Saad et al. 2013), limiting the opportunity to develop new CFs in a consistent manner.

The LANCA model is not available (Bos, 2014, personal communication), and the tailor-made version of the LANCA model that we developed based on the methodology report (Beck et al. 2010) may not sufficiently resemble the original model and thus cause some of the observed differences between county- and biome-level CFs. To support LCA practitioners who wish to use the proposed methodology to develop new CFs, this model needs to be made available.

Finally, some of the observed differences are likely due to different geographical scales of data extraction: averages from biome 4 may better represent conditions in the central parts of the biome than in the northern outskirts (Fig. S1, Electronic supplementary material S3).

\subsection{Setting the reference situation}

The UNEP-SETAC guideline (Koellner et al. 2013) requires the definition of a reference situation, i.e., a baseline to which the quality of ecosystem services in the assessed land use situation can be compared. It was defined here as the PNV and represented by deciduous (broadleaf) forest (Section 2.1.2). The reference situation needs to be assigned representative data, but the guideline lacks information regarding how this should be done in practice-from where and how to obtain representative data and how to handle data gaps. Here, we discuss challenges related to the definition (Section 4.2.1) and parameterization (Section 4.2.2) of the reference situation, and whether an alternative reference situation could be more informative (Section 4.2.3).

\subsubsection{Challenges in defining the reference situation}

The definition of the reference situation involves subjective choices, which the guideline acknowledges (Koellner et al. 2013). For example, it involves an assumption about time: is the PNV considered to represent conditions before the land was taken into use (if so, how long ago?); conditions that would develop in the future if the assessed land use ceased (at what point in the future?); or conditions that would exist at present if the assessed (or any other) land use had never been initiated?

As an example of how subjective choices can influence results, consider hydrological conditions. New cropland has historically been created in Sweden by clearing forests, lowering water tables in lakes, and draining wetlands. Considerable efforts were made to create new arable land, primarily during the first half of the twentieth century. According to one estimate, one sixth of the tilled farmland 
in Sweden was situated on former lakes and wetlands in 1950 (Hägerstrand and Lohm 1990). In addition to creating new cropland from lakes and wetlands, existing cropland prone to waterlogging was drained to improve yields. Approximately $55 \%$ of Swedish cropland had installed drainage systems in 2010 (Larsson et al. 2013).

A related parameter is the distance from surface to groundwater, required in the calculation of CFs for GWR and MFC. In reality, this distance depends on, e.g., the topology of the landscape, climatic conditions, and drainage. Saad et al. (2013) used a globally fixed value of $3 \mathrm{~m}$ (based on a study from Ontario, Canada; Stone and Myslik 2007) but acknowledged that this was associated with high uncertainty. We determined $2 \mathrm{~m}$ as a more accurate estimate for Sweden and applied this to both the reference and the assessed land use situations, due to lack of more precise information on hydrological conditions in historic times (Electronic supplementary material S9.1).

However, considering the historic large-scale drainage of cropland and wetlands in Sweden, it would have been equally valid to assume a shallower water table level in the reference situation. We evaluated the consequences of adopting an alternative definition of the reference situation on the CFs for MFC. When the effects of drainage were taken into account, the CFs for MFC increased (in absolute terms) by more than one order of magnitude and changed from positive to negative values, indicating an ecosystem service improvement instead of an impairment (Table S31, Electronic supplementary material S16). The reason is that drainage makes more (drained) soil available for mechanical filtration.

With regard to this alternative outcome, we identify two main problems: (1) the definition of the reference situation is a critical, yet subjective, part of deriving CFs, with serious implications for comparability between CFs derived by different LCA practitioners; and (2) the idea that "drainage benefits the water purification potential of the soil" (as suggested by this result) may not be correct, since drainage also increases the flow rate of water through the soil-which may counteract the increased availability of drained soil. Research has linked increased drainage of cropland in North America to increased leakage of nitrate and other soluble contaminants from agricultural lands (Blann et al. 2009) — which may be a sign of reduced water purification potential, although it is difficult to separate the effects from different agricultural management practices that are often applied in tandem (such as drainage and increased use of synthetic inputs). Thus, the definition of the reference situation and the associated assumptions - on which CFs depend - must be clearly communicated. Also, the validity of the assessment method for MFC should be further evaluated in light of new research (see Section 4.3).

\subsubsection{Challenges in parameterization}

Milà i Canals et al. (2007) recommended a parameterization approach based on interpolating data from neighboring grid cells that are representative of the selected reference situation. This can be challenging, not only since LCA practitioners may lack the required expertise in soil and geosciences to be able to identify such representative grid cells (i.e., land areas), but also since neighboring land areas that are representative of the reference situation may not exist, or the associated data may not be available. Also, using data from one region to represent conditions elsewhere is problematic considering varying pedoclimatic conditions. The main challenges encountered in parameterizing the reference situations with representative data are listed in Table 1. Two examples are discussed in more detail below.

County-level CFs for PFC indicate that agricultural production in VG and OG is associated with an improvement in the water purification potential of the soil, relative to the reference situation (Table 3). This contradicts the global trend of decreasing capacity of ecosystems to purify water (MEA 2005). A well-managed cropland can have a higher $\mathrm{CEC}_{\text {eff }}$ than the same land in an unmanaged state since inputs of manure and lime raise the organic matter content and the $\mathrm{pH}$ of the soil, and consequently the $\mathrm{CEC}_{\text {eff }}$, but our $\mathrm{CFs}$ most probably exaggerate the benefits of the assessed land uses due to challenges in finding suitable land areas from which to derive representative data. We parameterized the reference situations with measured $\mathrm{CEC}_{\text {eff }}$ data from soils in forests with both coniferous and deciduous trees (Electronic supplementary material S6.1). This approach resulted in 3-4 times lower levels of $\mathrm{CEC}_{\text {eff }}$ in the reference situations than in the assessed land use situations (Table S12, Electronic supplementary material S10.1). Forest soils generally have a coarser soil texture (less clay) than many cropland soils, which partly explains why these land areas have not been converted to arable land, or been abandoned. Approximately $20 \%$ of the land in OG and VG is used as arable land (Statistics Sweden Database 2015), and this fraction probably has above-average soil qualities (in terms of fertility, texture, slope, etc.). Hence, it is problematic to use $\mathrm{CEC}_{\text {eff }}$ data even from nearby forest areas to represent conditions in the reference situation, without accounting for differences in, e.g., soil texture and organic matter content. Thus, our approach to parameterizing the reference situations probably underestimates the reference $\mathrm{CEC}_{\text {eff }}$, resulting in exaggerated benefits of the assessed land uses. The same reasoning applies to $\mathrm{CFs}$ for SOC and CFC in terms of SOC stocks.

Finding suitable land areas from which to derive representative data is especially troublesome in regions with a long history of human influence. Agriculture has influenced land for almost 6000 years in southern Sweden, and archeological excavations have found that land use has varied considerably 
throughout history (Pettersson 1999). Swedish agricultural statistics cover approximately 200 years and are considered to be of high quality, but land use data for the late nineteenth century are nevertheless uncertain (SBA 2005).

Also illustrating the difficulty in finding suitable land areas that represent the reference situation is the fact that almost all forests in southern Sweden are managed, and less than $2 \%$ are classified as native (SEPA 2014b). Managed forests are usually planted with single species, typically spruce in southern Sweden. Coniferous trees, such as spruce, reduce the soil $\mathrm{pH}$ and hence the $\mathrm{CEC}_{\text {eff }}$ compared to the expected "natural" state. Managed forests are thus not fully representative of the PNV. In our parameterization approach, only 14 and 18 soil samples from $\mathrm{OG}$ and $\mathrm{VG}$, respectively, were available to determine the reference $\mathrm{CEC}_{\text {eff }}$ level (Table S12, Electronic supplementary material $\mathrm{S} 10.1$ ).

Parameterizing the reference situation with evapotranspiration data poses another challenge. We used evapotranspiration data from forested land areas in the respective regions (Electronic supplementary material S6.2). However, other parameterization approaches could have been used. We tested alternative approaches and evaluated the effects on cropland CFs for GWR in VG and OG (Table S32, Electronic supplementary material S16). Alternative 1 (using evapotranspiration data from areas with arable land) corresponds to the assumption that evapotranspiration remains fixed between the reference and the assessed land use situations. Alternative 2 (using county-average evapotranspiration data) corresponds to the situation that land use specific data are not available. Alternative 3 (using CFs from Table 3) corresponds with the view that evapotranspiration is higher if an area is forested than if the same area only has partial surface cover vegetation. In alternative 1, VG-dairy is associated with a greater negative impact than OG-pork, whereas in alternatives 2 and 3, the opposite is true. Thus, by using different parameterization approaches, different results and conclusions are reached.

\subsubsection{Would an alternative reference situation be more informative?}

We have discussed some challenges in setting the reference situation based on the PNV concept (Sections 4.2.1-4.2.2). The use of PNV as a basis for defining the reference situation is problematic since it implicitly relies on a theoretical idea about stable natural ecosystem "end-states," when natural ecosystems in reality are dynamic and subject to changing biophysical factors and events such as storms, fires, and insect outbreaks. The yearly changes in forest carbon stocks in Canadian managed forests are illustrative in this regard (Fig. 3). As can be seen, harvest removal is the most constant flux. A decline in living biomass (year 2000) and increase in dead biomass was largely due to fires in 1995 and 1998, and an insect outbreak the same year.
Chiarucci et al. (2010) discuss the problem of scarce longterm datasets and benchmarks of species composition in pristine vegetation in Europe and argue that PNV characterization that uses data for existing mature vegetation ignores the fact that vegetation is dynamic and continuously changes into nonanalogue assemblages of species. PNV is therefore considered impossible to model due to methodological problems related to ecosystem dynamics. If the PNV cannot be defined or parameterized in satisfactory ways, or is not relevant as a basis for defining reference situations, other ways to support land use impact assessment need to be found. Udo de Haes and Lindeijer (2002) discuss different alternatives and suggest that the current renaturalization potential of the land is the most consistent choice, i.e., the end-state that would emerge if the current land use ceased and conditions evolved in the absence of human influence. Another possible reference situation discussed by Udo de Haes and Lindeijer is that which existed before humans started to significantly influence ecosystems and biogeochemical cycles. Milà i Canals et al. (2007) proposed the use of a "dynamic reference situation" in order to account for changing conditions in the real world. They stress that this reference situation should represent the nonuse of the area and be defined consistently with the goals of the study. In some instances, it may be useful to abandon the reference situation altogether and directly attribute absolute impacts to the assessed land use situation (see, e.g., Cherubini et al. 2011; Bright et al. 2012; Guest et al. 2013). Soimakallio et al. (2015) reviewed the use of reference situations in attributional LCA studies and found that a majority did not use a reference situation, although land use was considered highly relevant for a majority of the reviewed studies.

To conclude, the choice of a reference situation is a critical step since it can strongly influence the results and conclusions of the study (cf. system boundaries). At the same time, the choice is not straightforward and may vary from case to case. A continued discussion on different alternatives, aiming at a more harmonized view on the choice of reference situation and more guidance on its parameterization, should benefit LCA practitioners who wish to assess land use impacts, as well as enhance the potentials for cross-study comparisons.

\subsection{Indicator evaluation and uncertainties}

Here, we discuss the results from the indicator evaluation and associated uncertainties.

Sources of uncertainty in this study are as follows: (1) spatial and temporal variability and uncertainty in input parameters, (2) uncertainty related to models and indicators, and (3) uncertainty related to choices.

Spatial and temporal variability in input parameters is caused by natural variations in the real world. County-level CFs are probably associated with lower variability and hence are more accurate than biome-level CFs, due to lower spatial and temporal 
Fig. 3 Yearly changes in carbon in the living biomass and dead organic matter pools in Canadian managed forests between 1990 and 2008 .

Harvested wood products were considered together with net ecosystem changes because they represent carbon that is taken out of the atmosphere. Figures prepared by D. Paré based on Stinson et al. (2011)

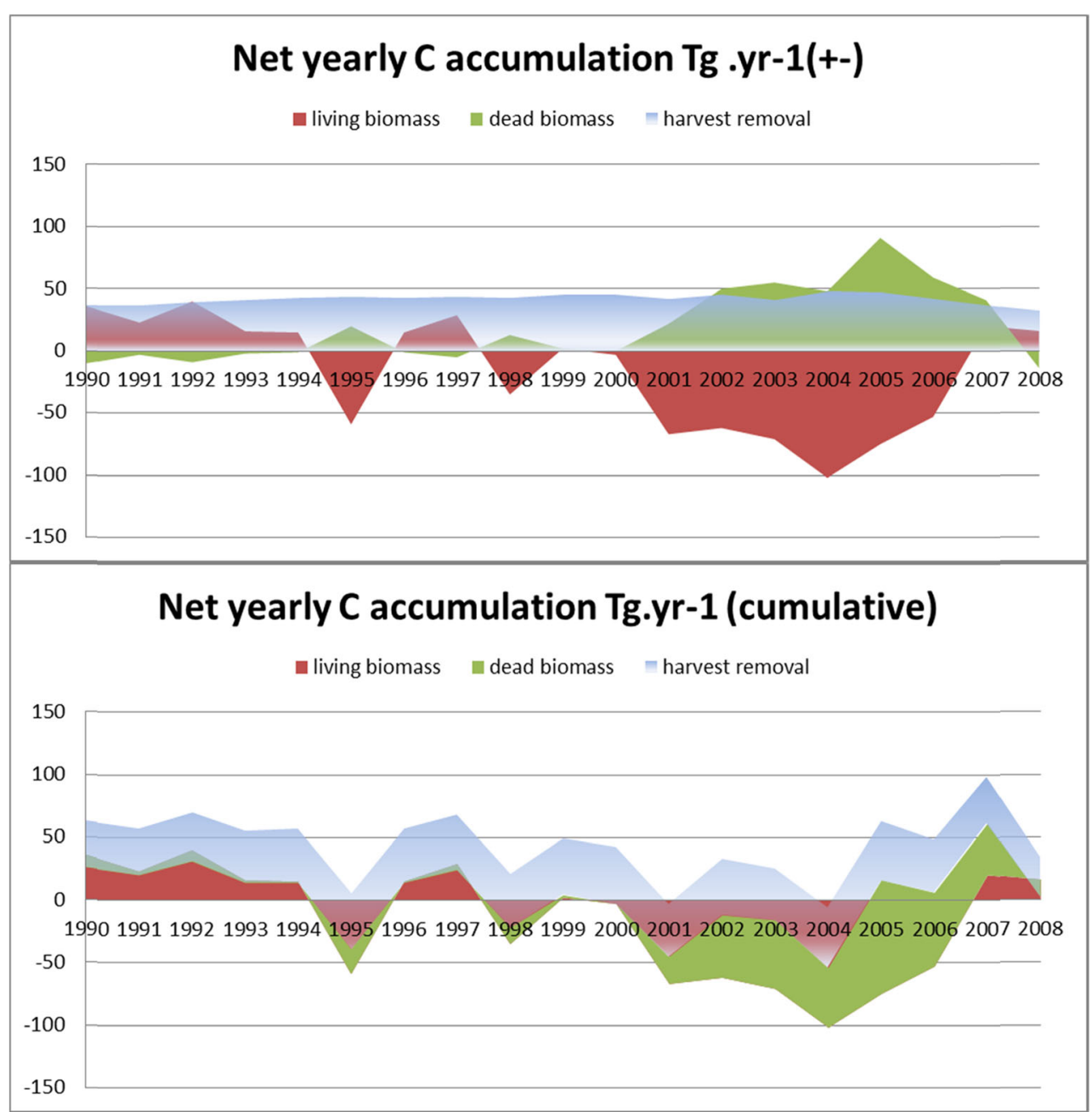

variability in geographically smaller regions. Uncertainty in input parameters is caused by, e.g., imprecise measurements and extrapolation methods used to generate missing data. For example, we estimated SOC stocks in the upper $1 \mathrm{~m}$ of the soil based on measured data in the upper $20 \mathrm{~cm}$ of the soil, using an extrapolation method developed in another region (Electronic supplementary material S13). Using an extrapolation method to generate missing data introduces uncertainty, and the fact that this method was not specifically developed for use in our studied regions adds to the uncertainty.

Maximum and minimum values, as well as standard deviations, indicate the uncertainties associated with several of the main input parameters (Electronic supplementary materials S5-14). Since we were not able to determine uncertainty distributions for all input parameters, we could not perform a fullscale, quantitative, uncertainty analysis including multiple parameters (e.g., Monte Carlo simulation). However, we assessed the sensitivities to a selection of key input parameters used in calculating CFs for GWR and MFC (Section 4.2).

More significant, and possibly overshadowing the uncertainties associated with input parameters, are the uncertainties related to models, indicators, and choices. The sensitivity analyses in Section 4.2 showed that alternative choices can significantly influence outcomes and result in different conclusions. One approach to reduce these uncertainties is through standardization (Huijbregts 1998). A more standardized framework for land use impact assessment, aimed at minimizing subjective choice, could reduce choice-induced uncertainties and facilitate cross-study comparisons.

The indicator evaluation revealed strengths and weaknesses of the indicators proposed by UNEP-SETAC (Section 3.3). Uncertainties related to models can be reduced by addressing these weaknesses. Reliability can, e.g., be increased by validating models against the real world, more clearly motivating the selection of indicators, and updating models in response to new knowledge. For example, in the model by Brandão and Milà i Canals (2013), it is assumed that reduced till and no-till increase SOC stocks in cropland by 8 and $15 \%$, respectively, compared to full tillage. However, new research suggests that the increase in SOC in the top soil from reduced till is merely a redistribution of the carbon in the soil profile (Powlson et al. 2014). This implies that biomelevel CFs for SOC may exaggerate the benefits of the assessed land uses. 
While reliability and representativeness are connected, there is a trade-off between reliability and representativeness on the one hand, and biogeographic resolution - related to feasibility — on the other. Increasing the biogeographic resolution (i.e., the level of regionalization) may increase accuracy but at the cost of increased data demand, as illustrated by a comparison between rates of soil loss estimated with LANCA and RUSLE (Section 3.1.5): erosion rates estimated with the more accurate model operating on a finer spatial scale (RUSLE) more closely matched modeled and measured erosion rates from the literature. However, due to the low feasibility of using RUSLE, a simplified version (such as LANCA) is probably needed to enable application in LCA.

The conversion of ecosystem service indicators into impact indicators (i.e., $\mathrm{CFs}$ ) increases representativeness but reduces transparency. Transparency is reduced since CFs are counterintuitive in the sense that positive CFs represent negative impacts, and negative CFs represent positive effects. Although this is in line with the general principles of LCA, clear communication of the interpretations is essential. Results concerning impacts on ecosystem services may be more prone to misinterpretations than the traditional LCA impact categories (e.g., climate change or ecotoxicity), since the traditional LCA impact categories intuitively have negative connotations, while ecosystem services intuitively have positive connotations.

The fact that CFs only indicate changes in quality, and do not inform about the actual levels of quality, is another reason $\mathrm{CFs}$ can be challenging to interpret. For example, county-level CFs for GWR indicate that cropland use is associated with a greater negative impact in $\mathrm{OG}$, than in $\mathrm{VG}$, due to a greater relative reduction in recharging capacity in $\mathrm{OG}$, than in VG (Section 3.1.2). The capacity of croplands to recharge groundwater was reduced by $15 \%$ in OG, compared to only $3 \%$ in VG. However, in absolute terms, the recharging capacity is greater in VG in the reference as well as in the assessed land use situations. A similar "phenomenon" was observed with county-level CFs for MFC (Section 3.1.3), where cropland ecosystems were assigned a greater negative impact in VG than in OG, despite cropland soils in VG being more sandy and less clayey and therefore more permeable (which is beneficial for the filtration capacity) than in OG. The assessment of some CFs implies that a higher initial state of quality leads to a greater relative reduction, i.e., greater negative impact.

Since the CFs do not inform about the actual levels of quality and do not take into account that impacts are condition-dependent (due to varying environmental sensitivities), and that thresholds may exist, wrong conclusions may be drawn concerning impacts - and risks - associated with the assessed land uses. For example, if land use situation $\mathrm{A}$ is attributed a greater negative impact on a specific ecosystem service than land use situation $\mathrm{B}$, and, at the same time, land use situation A has a relatively greater capacity to support this ecosystem service than land use situation B (Fig. 4), land use situation B may still be more damaging - and pose a greater risk - than land use situation $\mathrm{A}$, due to the lower support capacity of land use situation B. This would need to be clearly communicated.

For some ecosystem services, context conditions and threshold values are important, and it would be useful to relate CFs to these. For example, Pfister et al. (2009) describe an approach that captures local context conditions in an assessment of the impacts of water consumption in cotton production, by considering location-specific freshwater availability and use patterns.

\section{Conclusions and recommendations}

At the biome level, occupation impact results suggest that protein production from dairy milk is associated with lesser negative impacts or greater positive effects, i.e., ecosystem service improvements, compared to protein production from pork, as measured by five of six ecosystem service indicators, due in part to the positive effects of grass production on dairy farms and in part to the lower use of land per unit protein in milk production.

At the county level, occupation impact results are more mixed; VG-dairy scores better than OG-pork for CFC, GWR, and SL, while OG-pork scores better than VG-dairy for MFC, PFC, and SOC. Although OG-pork scores better than VG-dairy as measured by MFC, PFC, and SOC, VGdairy is nevertheless associated with positive effects for two of these (PFC and SOC), but these positive effects may be exaggerated, due to, most likely, underestimated reference soil qualities. Due to existing uncertainties caused by challenges in applying the methods, and the use of indicators with identified weaknesses, results should be interpreted with caution, and foremost be used to support further methodological developments.

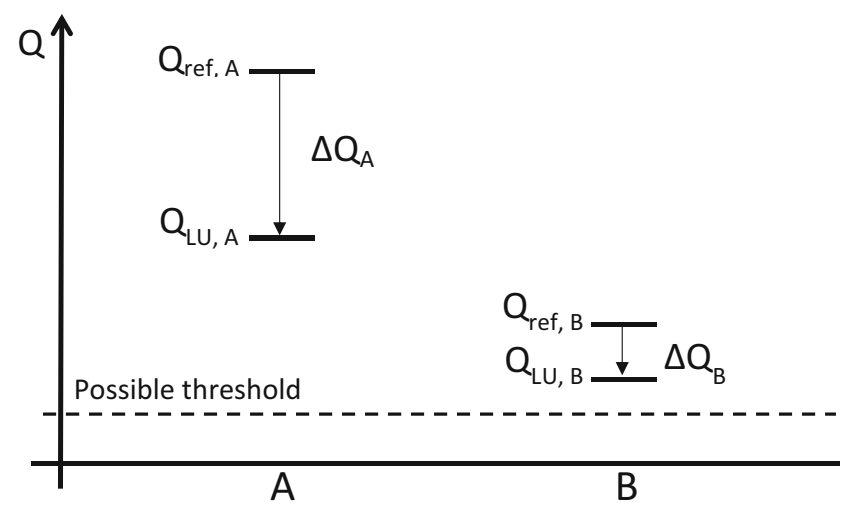

Fig. 4 Differences $(\Delta)$ in ecosystem quality $(Q)$ between the reference (ref) and the assessed land use (LU) situations in A and B. Characterization factors equal $\Delta Q$ 
The two most challenging parts of developing regionalized CFs were (1) to find suitable land areas from which to derive representative data to parameterize the reference situations, since areas that resemble the PNV are limited in Sweden, and (2) to cope with lack of support in applying the methods to develop regionalized CFs. Sensitivity analyses showed that alternative definitions and parameterizations of the reference situation can significantly influence outcomes and result in different conclusions (cf. system boundaries). More research is needed to clarify how the reference situation should be defined in relation to the goal and scope of the study.

Effective assessments of land use impacts on ecosystem services require the use of appropriate indicators. We identified strengths and weaknesses of the ecosystem services indicators tested here. Most were assigned medium or high degrees of representativeness, feasibility, and transparency. However, several indicators (CFC, GWR, MFC, PFC, and SL-LANCA) were assigned low degrees of reliability due to a weak scientific basis for indicator selection: low degrees of accuracy and insufficient detail regarding indicator assessment (e.g., from what soil depth to derive data). Uncertainties associated with models can be reduced by addressing these weaknesses. Reliability can, e.g., be increased by validating models against the real world, more clearly motivating the selection of indicators, and updating models in response to new knowledge.

The literature on ecosystem services contains a huge variety of indicators that have been proposed for measuring various aspects of ecosystem goods, services, processes, structures, and functions (see, e.g., Feld et al. 2009; Egoh et al. 2012; Crossman et al. 2013). We recommend that a wide set of potential indicators be considered carefully, based on the relevant quality characteristics. To make land use impact assessments more comprehensive, additional important ecosystem services, e.g., detoxification of hazardous substances, pollination, and cultural values, should also be considered for inclusion. Also, we recommend that alternative approaches to parameterizing the reference situations be considered, in order to potentially resolve some of the challenges identified here. For example, instead of identifying and extrapolating data from neighboring grid cells that are considered representative, reference conditions could be modeled or estimated based on conditions in the assessed land use situation.

We want to highlight the importance of assessing impacts on ecosystem services at appropriate scales, determined based on the goals and scope of the study, the characteristic spatial and temporal scales of the ecosystem services, scales at which decisions that influence the ecosystem services are applied, and scales at which data are available (see Alcamo et al. 2003). The county level (as used here) is an appropriate scale from a policy, governance, and data availability point of view but may not be the most appropriate scale from an environmental point of view. More research is needed in order to determine at what scales different ecosystem services are most appropriately assessed and how these scales can be used in LCA of land-based products. Also, more research is needed to develop more informative CFs that take into account local variations in sensitivity as well as potential thresholds.

Including the potential impacts on ecosystem services (and biodiversity) in LCA studies of biobased products is important, but several challenges need to be addressed before results can be presented and used with confidence. In particular, the circumstances under which land use impact assessments can yield valuable insights must be clarified - including at what scales - cf. the discussion on the role of LCA in decisionmaking (see for example Plevin et al. 2014 and Brandão et al. 2014). It is also important to ensure traceability along supply chains, since many products incorporate raw materials derived from multiple locations around the globe.

Further, in recognition of the inherent uncertainties and limitations associated with LCA, researchers who wish to support decision-making should also take advantage of other available tools. Indeed, most studies that assess ecosystem services use non-LCA methods (see, e.g., the reviews by Andrew et al. 2015 and Crossman et al. 2013). One commonly used tool is the InVEST model for integrated valuation of ecosystem services and trade-offs (Sharp et al. 2015). It can also be valuable to apply a landscape, rather than a product, perspective when assessing land use impacts on ecosystem services. Landscape management of ecosystem services (including, e.g., the provision of food) needs to consider social, economic, and environmental aspects, including synergies and trade-offs in situations where there are conflicting objectives. Knowledge and information from a broad range of stakeholders and from a multitude of scientific disciplines are needed to inform such management as well as to guide development of policy.

Acknowledgments We would like to thank the following persons and organizations for data provision and consultation: B. Thunholm and G. Sundén, Geological Survey of Sweden; J. Stendahl, Swedish University of Agricultural Sciences; U. Bos, University of Stuttgart; T. Koellner, University of Bayreuth; and D. Paré, Natural Resources Canada. Special thanks to two anonymous reviewers for valuable comments on this manuscript, to R. Saad for valuable discussions, to O. Englund for GIS support, and to P. Essunger for language edits. Financial support from the Swedish Energy Agency is gratefully acknowledged.

Open Access This article is distributed under the terms of the Creative Commons Attribution 4.0 International License (http:// creativecommons.org/licenses/by/4.0/), which permits unrestricted use, distribution, and reproduction in any medium, provided you give appropriate credit to the original author(s) and the source, provide a link to the Creative Commons license, and indicate if changes were made. 


\section{References}

Alcamo J, Ash NJ, Butler CD, Callicott JB, Capistrano D et al (2003) Millenium Ecosystem Assessment. Ecosystems and human wellbeing: a framework for assessment. World Resources Institute, Island Press, Washington

Allacker K, De Souza DM, Sala S (2014) Land use impact assessment in the construction sector: an analysis of LCIA models and case study application. Int J Life Cycle Assess 19:1799-1809

Andrew ME, Wulder MA, Nelson TA, Coops NC (2015) Spatial data, analysis approaches, and information needs for spatial ecosystem service assessments: a review. GIScience \& Remote Sensing 52: 344-373

Baitz M (2002) Die Bedeutung der funktionsbasierten Charakterisierung von Flächen-Inanspruchnahmen in industriellen Prozesskettenanalysen - ein Beitrag zur Ganzheitlichen Bilanzierung. Ph.D thesis (in German), University of Stuttgart

Beck T, Bos U, Wittstock B, Baitz M, Fischer M, Sedlbauer K (2010) LANCA - land use indicator value calculation in life cycle assessment-method report. Fraunhofer Institute for Building Physics; University of Stuttgart, Chair of Building Physics (LBP), Echterdingen

Blann KL, Anderson JL, Sands GR, Vondracek B (2009) Effects of agricultural drainage on aquatic ecosystems: a review. Crit Rev Environ Sci Technol 39:909-1001

Brandão M, Milà i Canals L (2013) Global characterisation factors to assess land use impacts on biotic production. Int J Life Cycle Assess 18:1243-1252

Brandão M, Clift R, Cowie A, Greenhalgh S (2014) The use of life cycle assessment in the support of robust (climate) policy making: comment on "Using attributional life cycle assessment to estimate climate-change mitigation ...". J Ind Ecol 18:461-463

Bright RM, Cherubini F, Strømman AH (2012) Climate impacts of bioenergy: inclusion of carbon cycle and albedo dynamics in life cycle impact assessment. Environ Impact Assess Rev 37:2-11

Büttner G, Kosztra B (2007) CLC2006 technical guidelines. European Environment Agency, technical report

Cao V, Margni M, Favis BD, Deschenes L (2015) Aggregated indicator to assess land use impacts in life cycle assessment (LCA) based on the economic value of ecosystem services. J Cleaner Prod 94:56-66

Cerdan O, Govers G, Le Bissonnais Y, Van Oost K, Poesen J, Saby N, Gobin A, Vacca A, Quinton J, Auerswald K, Klik A, Kwaad FJPM, Raclot D, Ionita I, Rejman J, Rousseva S, Muxart T, Roxo MJ, Dostal T (2010) Rates and spatial variations of soil erosion in Europe: a study based on erosion plot data. Geomorphology 122: 167-177

Cherubini F, Peters GP, Bernsten T, Strømman AH, Hertwich E (2011) $\mathrm{CO} 2$ emissions from biomass combustion for bioenergy: atmospheric decay and contribution to global warming. GCB Bioenergy 3: 413-426

Chiarucci A, Araújo MB, Decocq G, Beierkuhnlein C, FernándezPalacios JM (2010) The concept of potential natural vegetation: an epitaph? J Veg Sci 21:1172-1178

Coelho CRV, Michelsen O (2014) Land use impacts on biodiversity from kiwifruit production in New Zealand assessed with global and national datasets. Int J Life Cycle Assess 19:285-296

Crossman ND, Burkhard B, Nedkov S, Willemen L, Petzt K, Palomo I, Drakou EG, Martín-Lopez B, McPhearson T, Boyanova K (2013) A blueprint for mapping and modelling ecosystem services. Ecosyst Serv 4:4-14

Crutzen PJ (2002) Geology of mankind. Nature 415:23

Egoh B, Drakou EG, Dunbar MB, Maes J, Willemen L (2012) Indicators for mapping ecosystem services: a review. JRC (Joint Research Centre) Scientific and Policy Reports. Publications Office of the European Union, Luxembourg
Elshout PMF, Van Zelm R, Karuppiah R, Laurenzi IJ, Huijbregts MAJ (2014) A spatially explicit data-driven approach to assess the effect of agricultural land occupation on species groups. Int J Life Cycle Assess 19:758-769

Eriksson CP, Holmgren P (1996) Estimating stone and boulder content in forest soils-evaluating the potential of surface penetration methods. Catena 28:121-134

Eriksson J, Mattsson L, Söderström M (2010) Tillståndet i svensk åkermark och gröda, data från 2001-2007. Swedish Environmental Protection Agency, Stockholm

FAO (2009) Global map of yearly actual evapotranspiration - 5 arc minutes (GeoLayer). Food and Agriculture Organization of the United Nations. FAO GEONETWORK. http://data.fao. org/map?entryId=750d56ca-f92a-405e-8bbc-302221d55917. Accessed 8 June 2015

Feld CK, Silva PMD, Sousa JP, Bello FD, Bugter R, Grandin U, Hering D, Lavorel S, Mountford O, Pardo I, Pärtel M, Römbke J, Sandin L, Jones KG, Harrison P (2009) Indicators of biodiversity and ecosystem services: a synthesis across ecosystems and spatial scales. Oikos 118:1862-1871

Fridman J, Holm S, Nilsson M, Nilsson P, Ringvall AH, Ståhl G (2014) Adapting National Forest Inventories to changing requirementsthe case of the Swedish National Forest Inventory at the turn of the 20th century. Silva Fennica 48

Guest G, Cherubini F, Strømman AH (2013) The role of forest residues in the accounting for the global warming potential of bioenergy. GCB Bioenergy 5:459-466

Guo LB, Gifford R (2002) Soil carbon stocks and land use change: a meta analysis. Glob Change Biol 8:345-360

Heidmann T, Olesen SE, Christensen BT (2002) Changes in soil C and N in different cropping systems and soil types. In: DIAS Report, Plant Production no. 81. Department of Crop Physiology and Soil Science, Research Centre Foulum, Tjele, Denmark, pp 77-86

Helin T, Holma A, Soimakallio S (2014) Is land use impact assessment in LCA applicable for forest biomass value chains? Findings from comparison of use of Scandinavian wood, agro-biomass and peat for energy. Int J Life Cycle Assess 19:770-785

Herold M, Woodcock CE, Di Gregorio A, Mayaux P, Belward AS, Latham J, Schmullius CC (2006) A joint initiative for harmonization and validation of land cover datasets. Geosci Remote Sensing IEEE Transac 44:1719-1727

Hijmans RJ, Cameron SE, Parra JL, Jones PG, Jarvis A (2005) Very high resolution interpolated climate surfaces for global land areas. Int $\mathrm{J}$ Climatol 25:1965-1978

Huijbregts MA (1998) Application of uncertainty and variability in LCA: part I: a general framework for the analysis of uncertainty and variability in life cycle assessment. Int J Life Cycle Assess 3:273-280

Hägerstrand T, Lohm U (1990) Regional studies of transformation: Sweden. In: Turner II BL, Clark WC, Kates RW, Richards JF, Mathews JT, Meyer WB (eds) The earth as transformed by human action: global and regional changes in the biosphere over the past 300 years. Cambridge University Press.

Jarvis A, Reuter HI, Nelson A, Guevara E (2008) Hole-filled seamless SRTM data V4, International Centre for Tropical Agriculture (CIAT)

Jobbágy EG, Jackson RG (2000) The vertical distribution of soil organic carbon and its relation to climate and vegetation. Ecol Appl 10:423-436

JRC (2012) Estimated soil erosion by water in Europe-agri-environmental indicators. Joint Research Centre, European Commission

Koellner T, De Baan L, Beck T, Brandão M, Civit B, Margni M, Milà i Canals L, Saad R, De Souza DM, Müller-Wenk R (2013) UNEPSETAC guideline on global land use impact assessment on biodiversity and ecosystem services in LCA. Int J Life Cycle Assess 18: $1188-1202$ 
Larsson T, De Maré L, Lindmark P, Rangsjö C-J, Johansson T (2013) Jordbrukets markavvattningsanläggningar i ett nytt klimat (in Swedish). Swedish Board of Agriculture, Jönköping

Lehmann A, Back V, Finkbeiner M (2016) EU product environmental footprint - mid-term review of the pilot phase. Sustainability 8:92

Lehmann A, Back V, Finkbeiner M (2015) Product environmental footprint in policy and market decisions: applicability and impact assessment. Integr Environ Assess Manage 11:417-424

Mattila T, Helin T, Antikainen R (2012) Land use indicators in life cycle assessment. A case study on beer production. Int J Life Cycle Assess $17: 277-286$

MEA (2005) Ecosystems and human well-being: synthesis. Millennium Ecosystem Assessment. World Resources Institute, Island Press, Washington, DC

Michelsen O, McDevitt JE, Coelho CRV (2014) A comparison of three methods to assess land use impacts on biodiversity in a case study of forestry plantations in New Zealand. Int J Life Cycle Assess 19: $1214-1225$

Milà i Canals L, Bauer C, Depestele J, Dubreuil A, Knuchel RF, Gaillard G, Michelsen O, Müller-Wenk R, Rydgren B (2007) Key elements in a framework for land use impact assessment within LCA. Int J Life Cycle Assess 12:5-15

Milà i Canals L, Rigarlsford G, Sim S (2013) Land use impact assessment of margarine. Int J Life Cycle Assess 18:1265-1277

Mueller C, De Baan L, Koellner T (2014) Comparing direct land use impacts on biodiversity of conventional and organic milk-based on a Swedish case study. Int J Life Cycle Assess 19:52-68

Müller-Wenk R, Brandão M. (2010) Climatic impact of land use in LCA - carbon transfers between vegetation/soil and air. Int J Life Cycle Assess 15(2):172-182

Nilsson P, Cory N, Wulff S (2014) Skogsdata 2014. Swedish University of Agricultural Sciences, Umeå

Olson DM, Dinerstein E, Wikramanayake ED, Burgess ND, Powell GV, Underwood EC, D'Amico JA, Itoua I, Strand HE, Morrison JC (2001) Terrestrial ecoregions of the world: a new map of life on earth. Bioscience 51:933-938

Pettersson M (1999) Arkeologiska utgrävningar av fossil åkermark - en metodstudie (Archeological excavations of fossil cropland). In: Ericsson E (ed) Odlingslandskapet och uppdragsarkeologi. Skrifter $\mathrm{Nr}$ 29. Riksantikvarieämbetet Arkeologiska undersökningar, Linköping, pp 61-73, ISSN 1102-187X

Pfister S, Koheler A, Hellweg S (2009) Assessing the environmental impacts of freshwater consumption in LCA. Environ Sci Technol 43:4098-4104

Plevin RJ, Delucchi MA, Creutzig F (2014) Using attributional life cycle assessment to estimate climate-change mitigation benefits misleads policy makers. J Ind Ecol 18:73-83

Powlson DS, Stirkling CM, Jat M, Gerard BG, Palm CA, Sanchez PA, Cassman KG (2014) Limited potential of no-till agriculture for climate change mitigation. Nat Clim Change 4:678-683

Renard KG, Foster GR, Weesies GA, McCool D, Yoder D (1997) Predicting soil erosion by water: a guide to conservation planning with the revised universal soil loss equation (RUSLE). Agriculture Handbook, Washington, pp 1-384

Rytter RM (2012) Stone and gravel contents of arable soils influence estimates of C and N stocks. Catena 95:153-159

Saad R, Koellner T, Margni M (2013) Land use impacts on freshwater regulation, erosion regulation, and water purification: a spatial approach for a global scale level. Int J Life Cycle Assess 18:12531264
Saikku L, Mattila T, Akujarvi A, Liski J (2015) Human appropriation of net primary production in Finland during 1990-2010. Biomass Bioenerg 83:559-567

Sasu-Boakye Y, Cederberg C, Wirsenius S (2014) Localising livestock protein feed production and the impact on land use and greenhouse gas emissions. Animal 8:1339-1348

SBA (2005) Svenskt jordbruk i siffror 1800 - 2004 (Swedish Agriculture in figures 1800 - 2004). Statistikrapport 2005:6 (in Swedish). Swedish Board of Agriculture, Jönköping

SEPA (2014a) Miljöövervakning (in Swedish)., Swedish Environmental Protection Agency, www.naturvardsverket.se/miljoovervakning. Accessed 17 Mar 2015

SEPA (2014b) Gammelskog (in Swedish). Swedish Environmental Protection Agency. http://www.naturvardsverket.se/Stod-imiljoarbetet/Vagledningar/Miljoovervakning/ Bedomningsgrunder/Skogslandskap/Gammelskog/. Accessed 21 Jan 2015

Shangguan W, Dai Y, Duan Q, Liu B, Yuan H (2014) A global soil data set for earth system modeling. J Adv Modeling Earth Syst 6:249263

Sharp R, Tallis HT, Ricketts T, Guerry AD, Wood SA, ChaplinKramer R et al (2015) InVEST + VERSION+ user's guide. The Natural Capital Project, Stanford University, University of Minnesota, The Nature Conservancy, and World Wildlife Fund

Soimakallio S, Cowie A, Brandao M, Finnveden G, Ekvall T, Erlandsson M, Koponen K, Karlsson PE (2015) Attributional life cycle assessment: is a land-use baseline necessary? Int J Life Cycle Assess 20(10):1364-1375

Statistics Sweden Database (2015) Stockholm and Örebro: Statistics Sweden. http://www.scb.se/en /Finding-statistics/. Accessed 17 Mar 2015

Stendahl J, Lundin L, Nilsson T (2009) The stone and boulder content of Swedish forest soils. Catena 77:285-291

Stinson G, Kurz W, Smyth C, Nielson E, Dymond C, Metsaranta J, Boisvenue C, Rampley G, Li Q, White T (2011) An inventory-based analysis of Canada's managed forest carbon dynamics, 1990 to 2008. Glob Change Biol 17:2227-2244

Stone RP, Myslik JP (2007) Assessing the potential for ground water contamination on your farm. Factsheet. Ontario Ministry of Agriculture, Food and Rural Affairs

Taelman SE, Schaubroeck T, de Meester S, Boone L, Dewulf J (2016) Accounting for land use in life cycle assessment: the value of NPP as a proxy indicator to assess land use impacts on ecosystems. Sci Total Environ 550:143-156

Udo de Haes HA, Lindeijer E (2002) The conceptual structure of life cycle impact assessment. In: Udo de Haes HA, Finnveden G, Goedkoop M, Hauschild M, Hertwich EG et al (eds) Life cycle impact assessment: striving towards best practice. SETAC, Pensacola, pp 209-226

Verburg PH, Neumann K, Nol L (2011) Challenges in using land use and land cover data for global change studies. Glob Change Biol 17: 974-989

Wei X, Shao M, Gale W, Li L (2014) Global pattern of soil carbon losses due to the conversion of forests to agricultural land. Sci Rep 4(4062): $1-6$

Yang D, Kanae S, Oki T, Koike T, Musiake K (2003) Global potential soil erosion with reference to land use and climate changes. Hydrol Processes 17:2913-2928 